\title{
GEOGRAFIA POLÍTICA E GEOPOLÍTICA: VELHAS E NOVAS CONVERGÊNCIAS
}

\author{
Célio Augusto da Cunha Horta ${ }^{1}$ \\ Universidade Federal de Minas Gerais
}

É bastante freqüente, no meio acadêmico, o questionamento sobre a "necessidade" de diferenciar, com precisão, a geografia politica da geopolitica. Pergunta-se: será mesmo relevante delimitar rigorosamente essas áreas do conhecimento? Trata-se de um procedimento adequado do ponto de vista epistemológico? Em outros termos: essas duas áreas do conhecimento apresentam diferenças históricas e ideológicas significativas a ponto de se precisar demarcar uma clara distinção? Por outro lado, vários autores utilizam-se dessas nomenclaturas sem essa preocupação demarcatória. Desta forma, tendem a aproximar, conceitualmente, geopolítica de geografia política. Neste último caso é possível caracterizar essa aproximação como sendo uma "negligência epistemológica" ou trata-se de uma postura pautada em determinada consciência filosófica?

Outro problema recorrente refere-se aos pesquisadores que reduzem os estudos de geografia política e geopolítica ao poder dos Estados nacionais. Vale relembrar que as relações entre espaço e poder transcendem a ação dos Estados; porém, os trabalhos de geografia política ou de geopolítica, de um modo geral, não vêm acompanhando, satisfatoriamente, os mais recentes movimentos politicamente organizados que atuam contra e/ou independentemente do Estado. Conseqüentemente, questiona-se: qual é o principal motivo dessa "persistência anacrônica" que restringe os objetos de pesquisa ao papel dos Estados nacionais. Há algum indício de superação desta postura conceitual-metodológica? Em um futuro bem próximo é factível pensar que haverá, pelo menos, um relativo preenchimento desta lacuna nos estudos de geografia política e geopolítica?

Parte-se da hipótese de que o primeiro problema levantado, provavelmente, tenha forte correlação com o método de investigação/interpretação utilizado para a

'Professor Assistente do Departamento de Geografia do Instituto de Geociências da UFMG. 
consideração dos conceitos geografia política e geopolítica. No caso do segundo problema, defende-se a idéia de que há também uma descontextualização conceitual que vem restringindo, ainda, o olhar de muitos pesquisadores diante das relações que envolvem território e política.

Portanto, este artigo visa apresentar algumas idéias sobre a adoção das nomenclaturas - Geopolítica e Geografia Política - e, também, objetiva realizar uma breve reflexão dos propósitos políticos que historicamente envolveram ambas áreas de conhecimento considerando-se, ainda, neste aspecto, a questão dos respectivos objetos de pesquisa. Entende-se, inclusive, que a produção de conhecimento relativa às duas áreas mencionadas tem influenciado, variavelmente, os significados que são atribuídos aos próprios termos. Espera-se, desta forma, contribuir para a desmistificação e a ruptura de alguns conceitos e preconceitos concernentes à geografia política e à geopolítica.

\section{Geografia política e geopolítica: conceitos e preconceitos}

Seguramente, o termo geopolítica foi proscrito há decênios, sob pretexto de que ele esteve estreitamente ligado à argumentação do expansionismo hitleriano. Mas, pelo mesmo motivo se baniu a biologia, da qual os teóricos nazistas das "raças superiores" fizeram o uso que se sabe?

(LACOSTE, 1997: 242)

Conforme colocado anteriormente, alguns pesquisadores - geógrafos, historiadores, cientistas políticos, etc.- aproximam, conceitualmente, geopolítica de geografia política. Entretanto, outros pesquisadores fazem questão de diferenciar ambas nomenclaturas. Há um desencontro - uma significativa distância epistemológica - das duas concepções que, por conseguinte, acaba limitando, de certa forma, as respectivas abordagens.

Para a segunda situação (aqueles que defendem uma "clara" distinção de ambos os termos), pode-se considerar que a centralidade do problema localiza-se no enfoque adotado para caracterizar historicamente as produções em geopolítica e em geografia política. Os conhecimentos classificados pelos mesmos como sendo mais próprios do campo da geopolítica foram reduzidos a um contexto específico: início do século XX até a Segunda Guerra. Ressalte-se que esse contexto é concebido somente segundo as idéias e os acontecimentos hegemônicos, o que acaba por obscurecer as contradições imanentes de qualquer processo. Além do mais, esses mesmos pesquisadores, acabam isentando (de forma não muito explícita) a Geografia Política de qualquer participação direta ao longo desse período.

Quanto a esses posicionamentos, há pelo menos, dois equívocos que devem ser apontados. O primeiro refere-se a um resguardo estranho da geografia política, 
como se os trabalhos identificados como provenientes da mesma colocassem-se neutros, ou seja, como se fosse banal a geografia política ter sido silenciosa (e/ou silenciada) diante de vários problemas inerentes às guerras mundiais, ao nazismo, etc. O segundo engano envolve o olhar desses estudiosos sobre os trabalhos de geopolítica, pois são vistos como se fossem exclusivos desse período.

Sobre o segundo equívoco, percebe-se que há um "congelamento" conceitual da Geopolítica nesse contexto reduzido às produções prevalecentes. Para esse grupo de pesquisadores, a geopolítica se limita aos trabalhos originários desse passado - como as do sueco R. Kjéllen, do inglês H. Mackinder, do general-geógrafo alemão K. Haushofer, do norte-americano A. Mahan, etc. Em 1924, por exemplo, na Alemanha, Haushofer "consagrava-se" por ser um dos fundadores da Revista de Geopolítica (Zeitschrift fur Geopolitik). A vinculação dessa Revista (e de seus estudos) com o expansionismo de guerra da Alemanha nazista parece ter aniquilado, para alguns estudiosos, qualquer outra conotação para a geopolítica distinta de algo que faça referência ao totalitarismo, a uma "Geografia da Guerra", etc.. De fato, quando insiste-se na condenação perpétua do conceito, a geopolítica é, rotulada - e não por acaso - como sendo uma "Geografia do Fascismo", um saber voltado às estratégias militares, um "exercício" de dominação estatal, etc.; a geopolítica não tem nenhum outro significado - diferente desses - para determinados pesquisadores ${ }^{2}$.

Contrariando essa perspectiva, geógrafos como Manuel Correia de Andrade e Hélio Evangelista, por exemplo, "libertam" a geopolítica desse estigma. Consideram, evidentemente, esse momento histórico como sendo relevante (e negativo do ponto de vista ético) na trajetória dos estudos geopolíticos, mas observam enfoques diferentes que foram produzidos no mesmo contexto e conseguem visualizar, também, significativas diferenças nos trabalhos que atualmente estão sendo desenvolvidos:

\footnotetext{
${ }^{2}$ José William Vesentini (1997: 21, 22 - 24), em texto de sua autoria ( $O$ apogeu e o declinio da geopolítica), "aprisiona" a geopolítica no contexto referido: "(...) uma categoria ou um conceito(...)devem ser sempre contextualizados, entendidos como um processo e uma relação datados, que têm um começo e um fim (...) Com o progressivo enfraquecimento do Estado nacional moderno, em especial com a globalização, a terceira revolução industrial e suas inovações tecnológicas, a geopolítica entra em declínio. O pensamento geopolítico se enfraqueceu e talvez até tenha se esgotado com o avanço da democracia (...)" Porém, mais recentemente, Vesentini (2000: 12) estabelece uma distinção entre as "geopolíticas clássicas" e as "novas geopolíticas:" "O objetivo deste livro é comentar as novas geopolíticas que surgiram a partir do final da década de 1980 (...) Como se poderá deduzir, embora o nome "geopolítica" continue a ser utilizado (com a ressalva de que muitos dos autores mencionados não fazem a menor questão desse rótulo), o approach - isto é, o enfoque, a abordagem - atualmente é outro". Vesentini (2000:27) considera o período clássico como sendo representado somente por estudos procedentes dessa geopolitica de dominação estatal, do nazismo, etc., e as "novas geopolíticas" como ideologicamente necessárias e resultantes, em grande medida, da mudança de contexto histórico: "Mas se o rótulo geopolítica foi retomado, pelo menos por alguns, os métodos e os pressupostos fundamentais dos geopolíticos considerados clássicos foram deixados de lado."
} 
Contrapondo-se a esta doutrinação geopolítica formou-se, nos últimos tempos, uma corrente de pensamento que defendia a libertação dos povos oprimidos e empobrecidos pela colonização e pela exploração estrangeira $e$, no plano interno, levantava o problema da dominação das "elites" sobre as classes menos favorecidas. Até certo ponto esta corrente remonta aos trabalhos de Elisée Reclüs (...) No Brasil o grande reabilitador da geopolítica de vanguarda foi Josué de Castro, em livro muito expressivo sobre a fome (1945). (ANDRADE, 1989: 7)

O período clássico, ${ }^{3}$ para os que compartilham dessa interpretação, não se restringe às produções de cunho "nazista", e no caso das pesquisas atuais, alegam que essas assumiram direções independentes de determinadas pesquisas desenvolvidas nesse contexto: "(...) Vários geógrafos, ligados a uma ideologia popular e libertária, vêm desenvolvendo estudos geopolíticos que se contrapõem à orientação clássica (...)" (ANDRADE, 1989: 7) ${ }^{4}$

Vale ressaltar ainda, que muitos dos ataques à geopolitica são, ainda hoje, acompanhados de relativa reverência à geografia política. E é mais do sabido, que muitas vezes, a geografia política produzida por Ratzel, por exemplo, contribuiu significativamente para a expansão imperialista alemã; também constituiu base para os estudos de Haushofer, no contexto da Alemanha Nazista. ${ }^{5}$

\footnotetext{
${ }^{3}$ Pode-se dividir as produções de geografia politica e de geopolítica em três momentos complementares: um primeiro que data do início dos estudos sistemáticos (final do século XIX e início do XX) e segue até o período inter-guerras (que pode ser compreendido, grosso modo, como o período clássico); um segundo momento marcado pela hegemonia dos Estados Unidos nas pesquisas e por produções originárias nas instituições de ensino militares de vários países periféricos (pós-guerra até meados dos anos de 1970); e um terceiro período (meados dos anos de 1970 até os dias atuais) que acompanha parcialmente o movimento "crítico" da Geografia e que, de certa maneira, é caracterizado como "Geografia Política Renovada" (na versão francesa atual essa Geografia Politica Renovada realiza forte aproximação com a geopolítica). Wanderley Messias da Costa elabora uma demarcação um pouco parecida com esta, porém, concebida apenas para a Geografia Política. Ver COSTA, W.(1992) Geografia Política e Geopolítica. São Paulo: Hucitec/USP.

${ }^{4}$ Para Manuel Correia de Andrade (1989), Reclüs (1830-1905) produziu uma geopolítica voltada para análise dos problemas provocados pela expansão colonial. Andrade (1989) ressalta, também, as publicações atuais da revista francesa Herodote (Hérodote - Revue de Géographie et de Géoplitique). Segundo ele, essa revista constitui importante referência teórica no campo da geografia e da "geopolítica libertária".

${ }^{5}$ No caso das produções do chamado período clássico, semelhanças e diferenças no campo conceitual e ideológico são notáveis no interior da própria geografia política. Camille Vallaux, importante representante da Geografia Política Clássica (francesa), utilizou-se de vários postulados ratzelianos para elaboração de suas idéias, porém, discordava de Ratzel quanto a sua concepção de espaço e os conseqüentes desdobramentos metodológicos decorrentes dessa concepção; colocado desta forma, considerava o livro de Ratzel (La géographie politique) como um manual do imperialismo. Ver COSTA, 1992:49.
} 
Wanderley Messias da Costa, importante referência nos estudos em geografia política, não consegue, entretanto, desvincular a geopolítica do espectro do nazismo; salienta ainda que a maior parte do conhecimento produzido pela geopolítica tem origem na geografia política. Portanto, para Wanderley, a mesma não deve ser colocada, simples e diretamente, como sendo uma área de contato entre a geografia política, a ciência política, a ciência jurídica, etc. Para esse geógrafo, a geopolítica constitui um saber teoricamente empobrecido em relação às análises geográficopolíticas de Ratzel, Vallaux, Hartshorne, etc. Segundò ele, a geopolítica

(...) é antes de tudo um subproduto e um reducionismo técnico e pragmático da geografia política, na medida em que se apropria de parte de seus postulados gerais, para aplicá-los na análise de situações concretas interessando ao jogo de forças estatais projetado no espaço. (COSTA,1992: $55)$.

O intercâmbio de idéias não deve ser confundido com uma suposta apropriação indevida de algo que não é exclusivo, ainda mais quando se trata de produção de conhecimento. E se concretamente a geopolitica utilizou-se de postulados genuínos da geografia política - com fins diversos - ela mesma, em vários momentos, colocou-se autonomamente em relação às produções acadêmicas da Geografia (não se restringindo, somente, ao âmbito da arte e da técnica - coma é, não raramente, acusada de se pautar). ${ }^{6}$ Entretanto, Wanderley Messias da Costa não aceita qualquer con(fusão) que se estabeleça entre a geopolítica e a geografia política. Em discordância dessa posição, o geógrafo Yves Lacoste, por exemplo, aproxima com relativa tranqüilidade a geopolítica da geografia (o que não significa que não tenha conhecimento de uma vertente nazista da geopolítica). ${ }^{7}$ Mas, Wanderley Messias da Costa e muitos outros, não concebem qualquer perspectiva que não se limite às produções hegemônicas do referido contexto. Yves Lacoste, conseqüentemente, neste âmbito, é condenado por Costa (1992: 259):

\footnotetext{
"Importante destacar também, que a produção no campo da geopolítica não deve ser reduzida ao "jogo de forças estatais."

'Será que não houve, também, uma vertente nazista (oculta) no âmbito de determinados conhecimentos classificados como sendo próprios da geografia política? Como caracterizar inúmeras produções de "inspiração Lablacheana" - na França, se colocavam, inclusive, desfavoráveis à existência de uma geografia política - que utilizavam-se da concepção de "gêneros de vida" como justificava à dominação colonial? E sobre os trabalhos de geografia politica que aprofundaram e, de certa forma, distorceram os postulados de Ratzel ? Segundo Antônio Carlos Robert de Moraes (1990:24) "Na concepção ratzeliana, a índole guerreira é posta como virtude, sendo através da conquista que se expandem os frutos da civilização (...)"
} 
Ele propõe agora uma "geopolítica crítica", como que tentando seduzir os mais reticentes. Uma geopolítica que seria comprometida eticamente com a paz, a democracia e a jusiçça social. O princípio é inquestionavelmente perfeito para a geografia (e as ciências em geral). O problema é o rótulo escolhido, que especialmente ali, na França, não poderia ser mais infeliz.

Essa citação parece demonstrar uma certa aversão à geopolítica (reduzida a um rótulo). De acordo, então, com essa lógica deve-se enterrar definitivamente Hitler e o nazismo, mas sacrificando - para sempre - a geopolítica! Negar o imperialismo e o fascismo, por exemplo, é politicamente importante e necessário; porém, defender a geopolitica não significa levantar bandeira nazista, nem ressuscitar Hitler. Estabelece-se, assim, a pior confusão; também por isso Bertha Becker é outra geógrafa criticada por usar a "nomenclatura proibida":

(...) sob a influência da "geografia crítica" francesa - em particular Yves Lacoste e seu grupo em torno da revista Hérodote - já se registram (também aqui) tentativas de "recuperar" a geopolítica, emprestando-lhe caráter distinto daquele da sua "fase maldita". Bertha Becker, por exemplo, propõe explicitamente esse resgate (...)

$\left(\right.$ COSTA, 1992: 226) ${ }^{8}$

Mais do que o uso de uma "nomenclatura proibida", qualquer forma de resgate crítico é condenado por parte de determinados pesquisadores que defendem a eliminação eterna da geopolítica. Segundo então esta linha de pensamento, os estudos territoriais relacionados aos poderes políticos devem estar sob o escopo epistemológico da geografia política, uma ramificação acadêmiça e neutra de uma "ciência pura"; e não possuidora de comprometimento ético-ideológico no decorrer de sua história!

A cisma de Wanderley Messias da Costa (1992: 228) em relação à geopolítica é manifestada mesmo nos trabalhos de relevante valor acadêmico:

A proposta teórica de Bertha Becker é inovadora sob todos os aspectos (...) Independente do rótulo pouco apropriado (por que não resgatar a Geografia Política, que afinal sempre gerou as "geopolíticas"?), o seu trabalho (e de seu grupo) é realmente notável, (...)

Parece, no entanto, que vários pesquisadores que negam a geopolítica baseiamse, predominantemente, em algumas das idéias de José William Vesentini, Wanderley Messias da Costa, etc. Quanto a essa provável particularidade, vale ressaltar que a mera reprodução das idéias, sem a realização de um a mínima reflexão, contribui

\footnotetext{
${ }^{8}$ Costa (1992) destaca, nesse livro (ver p.226-228), os argumentos de Bertha Becker.
} 
com a manutenção de equívocos conceituais que não se limitam a uma questão de posicionamento ideológico. Quando não há, portanto, uma formulação conceitual própria de Geopolítica e, em contrapartida, ocorre apenas absorção a-crítica de idéias que aprisionam a geopolítica ao nazismo corre-se o risco da recriação de preconceitos oriundos de postulados pré-fabricados.

Não se trata, portanto, de simplesmente "optar", ideologicamente, por uma ou outra - geopolítica ou geografia política. A geografia política, no seu trajeto histórico, agrega produções como as de Elisée Reclüs ou Kropotkin ${ }^{9}$, como também foi - e vem sendo - construída por representantes comprometidos com a manutenção do status quo ${ }^{10}$. O conhecimento geopolítico também comparece com elaborações como as de Haushofer ou, então, como as de Josué de Castro"'.

A praxis que envolve os trabalhos em geopolitica e em geografia política é diversa e contraditória no interior de ambas áreas de conhecimento; uma visão nada dialética e caracterizada por maniqueísmos corporativistas não consegue detectar essas diversidades. Por conseguinte, se ideologicamente as produções são variáveis (e não dicotomicamente opostas) ao ponto de ser equivocado estabelecer significativa distinção entre ambas, que elementos poderiam configurar as diferenças entre a geopolítica e a geografia política?

Do ponto de vista epistemológico, valorizar as várias semelhanças entre elas constitui um posicionamento mais adequado do que localizar as poucas diferenças; uma certa (con)fusão que se realize entre geografia política e geopolítica tornase, assim, normal e salutar. Compreender que historicamente desenvolveram-se, por parte de ambas, produções que corresponderam ora a um interesse de dominação, ora a uma práxis de libertação é mais relevante do que ficar procurando

\footnotetext{
'Para alguns estudiosos, Reclus produziu conhecimentos que são do âmbito da geopolítica; para outros suas produções pertencem à geografia política. O geógrafo russo, Pioter Alexeyevich Kropotkin (1842-1912), é como Reclüs, reconhecido por suas contribuições no campo temático do anarquismo comunista. Sobre Kropotkin e sua obra ver KROPOTKIN - Textos escolhidos; organização de Maurício Tratenberg (1987).

${ }^{10}$ José William Vesentini (1987: 24), apesar de inicialmente negar a geopolítica e considerar científica e ideologicamente positiva somente a geografia política, reconhecia "problemas epistemológicos" no seio dessa última: "A grande insuficiência da geografia política tradicional - desde Ratzel até algumas obras recentes (...) foi justamente a de não apreender a alteridade de cada situação, procurando estudá-las apenas a partir de noções genéricas e a-históricas, tais como função, sítio (...)"

${ }^{11}$ O médico e geógrafo Josué de Castro, produziu na década de 1940, importantes obras que destacaram o problema da fome no Brasil; mas nos anos de 1950 , ele ampliou a sua atuação, partindo para uma análise em escala mundial. Em 1951, foi publicado "Geopolítica da Fome", livro laureado pela Academia Americana de Ciências Políticas, com o Prêmio Franklin D. Rooselvelt e pelo Conselho Mundial da Paz, com o Prêmio Internacional da Paz.
} 
fronteiras segregacionistas que distanciam as mesmas ${ }^{12}$. Portanto, é válido estabelecer as diferenças e as semelhanças, mas deve-se tomar os devidos cuidados metodológicos.

Por outro lado, o uso dessas nomenclaturas sem o devido conhecimento epistemológico pode indicar, de certa forma, alienação original no trato com a pesquisa. Utilizações aleatórias são comuns e em alguns casos como salienta Wanderley Messias da Costa (1992: 55): "análises e estudos ditos geopolíticos podem freqüentemente tratar-se de estudos geográficos-políticos, preferindo os autores a utilização da primeira expressão por simples comodismo vocabular ou modismos." 13

O "simples comodismo" ou uma opção oportunista, por exemplo, correspondem a comportamentos retrógrados no âmbito da academia; entretanto, vale destacar que alguns pesquisadores concebem a geopolítica e a geografia política a partir de outros princípios metodológicos:

- não reduzem a geopolítica ao seu período clássico (limitado ou não às idéias nazistas);

- consideram que a geografia política - assim como a geopolítica - também elaborou (e ainda elabora) estudos destinados aos interesses de grupos hegemônicos voltados ao imperialismo, à dominação de classes, de gêneros, etc.;

- reconhecem que tanto a geografia politica quanto a geopolítica produziram (e atualmente produzem) trábalhos teoricamente relevantes, críticos e sustentados, muitas vezes, sobre um conjunto de valores eticamente compatível com idéias referentes ao desenvolvimento humano e social.

Colocados todos esses elementos, a "necessidade" (ou mesmo a possibilidade) de estabelecer distinções evidentes entre a geografia política e a geopolítica torna-se pouco consistente. Além das tentativas que visam firmar divergências ideológicas, são também comuns as que colocam a geografia politica como sendo mais teórica e acadêmica, enquanto a geopolítica seria mais pragmática, de uso corrente por aparelhos do Estado (como nas instituições militares, por exemplo). Wanderley Messias da Costa, contudo, reconhece:

\footnotetext{
12 Para o caso da geografia política e da geopolítica, pode-se dizer que a "Bela e a Fera" (com referência à obra de Jeanne-Marie Leprince de Beaumont) não são as duas - uma e outra - mas estão (simultaneamente) nas duas.

${ }^{13}$ Sobre essa questão, José William Vesentini (2000:10) pensa de maneira semelhante: “(...) Também com a geopolítica essa inflação terminológica vem ocorrendo, (...) A partir do final da década de 1980 , devido às mudanças radicais no mapa-múndi (...), a palavra geopolítica tornou-se moda. Hoje ela é usada, em alguns meios, para se referir a praticamente todas as discussões políticas e econômicas internacionais (...) algo que evidentemente torna essa palavra desprovida de qualquer significado preciso (...)"
} 
A própria discussão sobre as diferenças entre a geografia politica e a geopolítica fica, por assim dizer, "atravessada" (...) Rótulos como "básica e fundamental" para a primeira e "aplicada ou prática" para a segunda, não resolvem o problema de que (...) parte substantiva da geografia política tenha como que se tornado geopolítica (...)

(COSTA, 1992: 20) ${ }^{14}$

Uma pequena diferença que ainda pode ser considerada - guardadas as devidas proporções - relaciona-se ao fato de que a geografia politica trata-se, originalmente, de uma ramificação da geografia moderna; e a geopolítica, ${ }^{15}$ a princípio, era mais vinculada à ciência política. Evidentemente que os estudos geopolíticos não se restringem aos cientistas políticos e tão pouco somente geógrafos produzem trabalhos em "geografia política." Porém, é por meio desse singelo aspecto que pode-se perceber, com relativa nitidez, alguma distinção entre ambas. Considerase, portanto, que essa (relativa) diferença de origem situa-se no campo da "divisão acadêmica/científica/técnica do trabalho," mas que no decorrer do próprio desenvolvimento do conhecimento humano, essa mesma diferenciação vem tornandose ainda menos significativa. A aproximação dos conhecimentos disciplinares, a justaposição dos saberes ditos "populares" aos "saberes científicos", a inserção mais valorizada de conhecimentos filosóficos e de produções artísticas ${ }^{16}$ - dentre outras tendências - no conjunto superestrutural do capitalismo pós-fordista constituem, portanto, interseções próprias do atual contexto histórico-geográfico. Por conseguinte, a separação entre a geografia política e a geopolítica, mesmo neste aspecto, parece não se apresentar muito cabível.

Por uma questão, talvez, de semântica vinculada a esse resquício de origem acadêmico-disciplinar, parece ser mais compatível conceber a geopolítica como sendo mais interdisciplinar e, aparentemente, mais ampla do que a geografia política. No senso comum, observa-se ser "mais tranqüilo" afirmar que o que se elabora/realiza é geopolítica. Como já mencionado, do ponto de vista inter e

\footnotetext{
${ }^{14}$ Ver COSTA, W. (1992). A divisão entre o pensar e o fazer constitui, também, grave equívoco quando se insiste em estabelecer diferenças desse tipo; conceitos absurdos foram criados, como por exemplo: “(...)A geografia política apóia-se em observações estáticas dos fatores geográficos. Considera as fronteiras, os rios, as planícies (...) a geopolítica, pelo contrário, não se satisfaz com a mera descrição física (...) preocupa-se com os "movimentos" desses elementos, e com sua aplicação na formulação de uma política que visa a fins estratégicos (...)" (MIYAMOTO, 1985: 24, 25).

15 Juan Rudolph Kjellen (1864-1922), professor (sueco) de Direito Político das Universidades de Upsala e Gotemburgo, foi o pioneiro no uso do termo geopolítica (1899); porém, formulou melhor o conceito de geopolítica na obra intitulada "O Estado como forma de vida," publicada em 1910; considerava a geopolítica como um ramo autônomo da ciência política. Os trabalhos de Kjellen, inclusive, manifestam forte influência das idéias de Ratzel.

${ }^{16}$ Mesmo que concebidas - infelizmente - sob a ótica mercadológica dos protagonistas da globalização recente. Essas aproximações, inserções e justaposições manifestam os denominados trabalhos interdisciplinares, pluridisciplinares, transdisciplinares, multidisciplinares, etc.
} 
transdisciplinar a geopolítica pode ser produzida por geógrafo, cientista político, historiador, jurista, militar, diplomata, membro do MST (Movimento dos Sem Terra) no Brasil, etc. ${ }^{17}$ Assim sendo, no tocante às diferenças, à geografia política fica resguardada uma relativa especificidade de ordem acadêmica e "vocabular"? Provavelmente, ainda, em alguns casos, o termo geopolítica pode ser até mesmo colocado como abreviatura de geografia política. Terminologia usada não como forma de simples comodismo ou modismo (problema já comentado), mas muitas vezes, colocada por "simplificação-significação lingûística"18 - o que não tem, necessariamente, relação com reducionismos de natureza teórica e conceitual. Essa postura, conseqüentemente, acaba "velando" o teorizar/fazer geografia politica que vai além do exercício dos geógrafos, historiadores, etc. Por isso, também, fica aquela impressão de que a geopolítica é mais aplicada do que a geografia politica e essa última é mais teórica.

Importante ressaltar que é muito usual hoje, no meio universitário, a expressão "geografia política aplicada", que manifesta, inclusive, desdobramentos da chamada "Geografia Política Renovada". Neste âmbito, geógrafos como Yves Lacoste e Oliver Dollfus na França, Bertha Becker e Therezinha de Castro no Brasil, por exemplo, realizaram (desde os primeiros anos de 1970) maiores aproximações entre a geografia política e a geopolítica. Essas fusões e aproximações das nomenclaturas caracterizam, de certa maneira, interpretações epistemológicas que reconhecem as intrincadas e dialéticas relações existentes entre geopolítica e geografia política. Além do mais, manifestam o dinamismo inerente das terminologias e conceitos criados e recriados pela academia.

Para aqueles que ainda "precisam" separar - mesmo que pedagogicamente geografia politica da geopolitica, torna-se importante colocar novamente: em termos de objetos de investigação há diferenças evidentes? E em relação aos métodos de trabalho (incluindo, neste caso, a dimensão ideológica)? ${ }^{19}$

${ }^{17}$ Uma liderança do MST, ao projetar uma determinada ocupação territorial com e para um grupo de familias expropriadas, se colocaria - caso questionado - como que pensando/fazendo geopolítica ou geografia politica? Do ponto de vista da academia, como caracterizar o uso das duas terminologias para um processo desta natureza?

${ }^{18}$ Quando são feitas referências a processos que envolvam a relação território-politica "nossa língua" estimula a formulação em torno de processos geopolíticos ou geográfico-políticos?

${ }^{19}$ Algumas tentativas de estabelecer as referidas diferenças conduziram, por exemplo, a separação entre ideologia e ciência; Nelson Werneck Sodré considerava a geopolítica como pseudociência e reduzia a mesma a um conjunto de idéias (doutrina) que serve como ideologia de dominação. José William Vesentini (1987: 54-55) faz crítica relativa ao autor, mas acaba recaindo numa outra dicotomia (também equivocada), pois, segundo ele a geografia politica tradicional foi socialmente a-histórica, mas "não deixou de eventualmente envolver-se em tensões com o Estado (...) já a geopolítica é por definição um discurso do Estado(...)"; Diante, então, desta distinção ideológica dos "sujeitos históricos", José William Vesentini (1987: 67-68) afirma: "Pretender dissolver a geografia política na geopolítica, sob o argumento de que elas tratam do mesmo "objeto" (...) significa aproximar-se perigosamente de um comprometimento com a dominação (...)" 


\section{Geografia Política/ Geopolítica: consciência geográfica do território? ${ }^{20}$}

\section{O Estado certamente não é a unidade única representativa do político nem o território nacional a única escala de poder (BECKER: 1995: 303)}

Prevalece, ainda, uma concepção equivocada de que a geografia política e/ou a geopolítica formam um conjunto de conhecimentos vinculados, tão somente, ao poder e ação dos Estados nacionais. Parece que um "onipotente, abstrato e obscuro mapa das nações" colocou-se como representante de um pensamento majoritário, recorrente e limitador dos objetos de estudos de ambas áreas de conhecimento ${ }^{21}$.

Essa visão restritiva ${ }^{22}$ do campo de ação da geopolítica e da geografia política tem, provavelmente, relação com o contexto de formação e/ou expansão dos Estados nacionais. Segundo Wanderley Messias da Costa (1992: 58-59),

\section{(...) o surgimento da geografia política e sobretudo da geopolítica são um} produto do contexto europeu (...) com Ratzel e $R$. Kjélen (...) o interesse pelos fatos referentes à relação entre espaço e poder, também manifestava um momento histórico (...) caracterizado pela emergência das potências mundiais(...)

\footnotetext{
${ }^{20}$ Subtítulo provocativo à colocação original de Haushofer que sustentava que a geopolítica deveria ser a "consciência geográfica do Estado."

${ }^{21}$ Segundo Otto Schäfer: "A geografia política (...) mostra como o espaço influi no Estado, impondothe suas leis e, por assim dizer, submergindo-o. A geopolítica considera como o Estado supera as condições e leis do espaço e faz com que estas sirvam a seus propósitos (...). Em resumo: a geografia política encara o Estado do ponto de vista do espaço; a geopolítica encara o espaço do ponto de vista do Estado". Citado por VESENTINI (1987: 56). Porém, José William Vesentini (1987: 57), também reduz o objeto de investigação da geopolítica ao papel do Estado: “A geopolítica, então, é o discurso do Estado capitalista sobre o espaço geográfico; é o conhecimento (sempre voltado para a ação) que visa a assegurar e fortalecer a soberania de um Estado nacional tanto em relação aos demais Estados como sobre o seu território, no seio da sociedade onde ele encontra sua razão de existir". Entretanto, José Willliam Vesentini (2000: 11), ao fazer uma revisão parcial de algumas de suas idéias preliminares sobre geopolitica - utilizando-se como justificativa as mudanças decorrentes do atual contexto histórico - acaba por ampliar o seu conceito sobre a mesma: "(...)Por isso mesmo acreditamos que é possível falar em "novas geopolíticas," mantendo um significado relativamente preciso e delimitado da palavra - isto é, como um campo de estudos interdisciplinar que se refere à correlação de forças no plano espacial, com ênfase na escala mundial -, discutindo suas idéias e suas diferenças ante as geopolíitcas clássicas".

${ }^{22}$ Não se trata de um "objeto restrito", pois os estudos que envolvem o Estado, a sociedade e o território, por exemplo, são demasiadamente complexos. O que se questiona é a "exclusividade" do Estado diante de outras formas de poder institucional e territorial. Quanto a isso, Wanderley Messias da Costa (1992: 17-19) ressalta a importância dos estudos geográficos-políticos que consideram o significado político do Estado, porém defende a amplitude do "objeto teórico".
} 
Helio de Araújo Evangelista também adverte sobre o problema e ressalta a preponderância do período (fim do século XIX até a década de 1920) em que a geopolítica foi institucionalizada. Para ele, a geopolítica foi conectada ao Estado de tal maneira que passou a ter o papel de orientação de muitas das ações do próprio Estado:

(...) podemos notar que a disciplina surgiu sob a égide da análise do Estado. É como se a geopolítica tivesse como fundamento o estudo da articulação do Estado com uma determinada configuração espacial. Muito embora, pelo sentido etimológico da palavra, a relação entre geografia e a política não precisa estar limitada ao Estado.

(EVANGELISTA, 1995:226)

Para Claude Raffestin (1993:16) essa restrição - ainda persistente - pode ter correlação com a produção original de Ratzel: "Para Ratzel, tudo se desenvolve como se o Estado fosse o único núcleo de poder (...) a geografia política de Ratzel é uma geografia do Estado (...)". Vesentini (1987: 32) defende, também, que o objeto central da geografia política clássica "foi o território, concebido como espaço natural apropriado (ou apropriável) pelo Estado".

Paul Claval ${ }^{23}$ e Claude Raffestin criticam essa fetichização do Estado. De acordo com esses dois autores, os geógrafos estão ainda muito "apegados" à relação Estado-território negligenciando, assim, outras dimensões espaciais do poder (COSTA, 1992: 24). Portanto, as pesquisas devem, também, abordar - segundo eles - as relações de poder e o "fenômeno religioso" (incluindo a oposição entre o sagrado e o profano); o controle e gestão dos fluxos migratórios; a conexão das redes espaciais com as redes de comunicação particulares; a língua (e as linguagens) enquanto recurso de dominação; etc.

Complementando esse raciocínio, vale reforçar que o foco territorial deve, também, extrapolar a escala nacional. Desta forma, temas que tratem, por exemplo, das relações de poder num latifúndio ${ }^{24}$, em um pequeno município brasileiro, numa microbacia hidrográfica, etc, merecem ser estudados. Em síntese, outras instâncias de poder, outras territorialidades e diferentes formas de gestão da sociedade - e que em muitos casos estão, inclusive, conectados aos aparelhos de Estado constituem "objetos" de investigação que podem ser abordados em geopolítica ou

\footnotetext{
${ }^{23}$ Segundo Claval (1979: 215): "As dimensões espaciais dos fatos do poder foram negligenciadas. A geografia política voltou-se prematuramente para a análise do Estado e não soube dissecar as engrenagens dos governos e sua articulação sobre a sociedade civil. (...) O problema do poder é, em primeiro lugar, o da transmissão do fluxo de informações (...) o acesso às idéias novas, o controle da terra (...), o controle da mão-de-obra (...)"

${ }^{24}$ Carlos Walter Porto-Gonçalves (2002: 39-60), por exemplo, trata - dentre outros aspectos - de relações de poder nos latifúndios genéticos. Ver artigo intitulado "O latifúndio-genético e a r-existência indígeno-camponesa". In: GEOgraphia: Revista de pós-graduação em Geografia da UFF;; ano 4; nº 8.
} 
em geografia política. É importante reconhecer que a relação espaço-poder, muitas vezes, transcende o Estado. ${ }^{25}$ Nesse âmbito, Bertha Becker (1995: 271-272) ressalta que:

Num aparente paradoxo, as mesmas condições que induzem à revalorização da Geopolítica negam os pressupostos em que se tem assentado, a saber, o Estado como unidade política do sistema internacional, e o território como fundamento do poder nacional (...)

Considerando-se as alterações estruturais no cenário político e econômico mundial (do final do século XX) ${ }^{26}$, a geógrafa Bertha Becker (1995:272) destaca que as novas territorialidades desenvolvem-se acima e abaixo da escala do Estado e "desafiam os fundamentos do poder nacional e a possibilidade de desenvolvimento autárquico". ${ }^{27}$

Sobre a mudança do Estado no atual contexto - problemática que exige também novas abordagens por parte da geografia política/geopolítica - Nicos Poulantzas apontava, já nos anos de 1980, para o dilema político-funcional concernente à sua própria "evolução" histórica, bem como em decorrência das necessidades impostas pela estrutura econômica do capitalismo:

$O$ Estado está hoje de qualquer maneira preso a sua própria armadilha, e a metáfora não é exagerada: ele não pode daqui pra frente recuar nem avançar, nem abster-se nem controlar o núcleo central da economia. (...) $O$ atual Estado oscila perpetuamente entre os dois termos da alternativa, omitir-se elou participar no mais das vezes. (...)

(POULANTZAS, 1980: 22)

As pesquisas em geopolítica ou em geografia politica destinadas a tratar dos Estados nacionais permanecem muito relevantes, ainda mais quando consideradas as transformações atuais em sua conformação política e territorial. ${ }^{28}$ Porém, em

${ }^{25}$ Como destacado por Lefebvre, citado por Raffestin (1993:15): “É preciso dissipar a freqüente confusão entre Estado e poder. O poder nasce muito cedo, junto com a história que contribui para fazer."

${ }^{26}$ Levando-se em conta o fim da Guerra Fria, a revolução científico-tecnológica que transforma a base produtiva da economia, a crise ambiental, etc. (BECKER, 1995: 272-273).

27 "Trata-se, portanto, não do fim do Estado, mas de uma mudança em sua natureza, e seu papel, entendendo-se que ele não é uma forma acabada, é um processo. (...)" (BECKER, 1995: 272); Para Bertha Becker (1995: 298-299) o Estado não "é a única representação do político nem a única escala de poder, mas certamente é uma delas, (...)"

${ }^{28}$ A exemplo da União Européia, pois há metamorfoses tanto territoriais quanto nas instâncias políticas. O "velho" e "novo", inclusive, manifestam-se no âmbito das lutas nacionalistas (como os movimentos na Escócia, na Irlanda do Norte, no "país" Basco, etc.), na formação das instituições supranacionais (como o parlamento europeu), etc. 
razão inclusive dessas mudanças que outras organizações de poder e outras territorialidades devem compor, com maior vigor, objetos de interpretação em geografia política ou em geopolítica. A geógrafa Bertha Becker ressalta algumas temáticas emergentes apontando, por exemplo, a relevância da "ecologia como novo parâmetro geopolítico", o controle da biodiversidade, etc. ${ }^{29}$ Segundo a geógrafa:

A valorização da dimensão política do espaço também se relaciona à redefinição da natureza e das relações sociedade-natureza. Na medida em que a crise ambiental estabelece limites reais à exploração predatória de recursos naturais, o novo modo industrial atribui outro significado à natureza. (...) Mas a dinâmica contemporânea não decorre apenas da lógica instrumemtal (...) a lógica cultural, dos valores, expressa em movimentos sociais diversos, converge para o processo de diferenciação espacial e valorização estratégica dos territórios. (BECKER, 1995: 288-289).

A geografia política e a geopolítica configuram-se para muito além dos Estados nacionais. Delegar estratégias de organização política do espaço somente aos Estados significa, de fato, reduzir as relações espaço geográfico-política a um determinado contexto histórico-geográfico (concebido apenas segundo a lógica predominante das respectivas superestruturas). Há um vasto campo de análise que supera as pesquisas destinadas às "geopolíticas estatais". Na Geografia, ainda são escassos os estudos, por exemplo, sobre as geopolíticas de dominação dos impérios "précapitalistas" ${ }^{30}$ (como o Inca ou o Asteca), ou mesmo reflexões pertinentes às geopolíticas produzidas por "sociedades alternativas" que criaram, por exemplo, seus enclaves de resistência, como Palmares. É bem verdade que na França, desde os anos de 1980, já vem ocorrendo uma aproximação da geografia politica com a geografia cultural, o que tem permitido, muitas vezes, trabalhos do tipo: " $A$ geografia do poder nas sociedades arcaicas" (CLAVAL,1979). Entretanto, outras conexões poderiam ser realizadas mais solidamente: a geografia urbana com a geografia política, essa última com a geografia agrária, etc. ${ }^{31}$ Geopolíticas que

${ }^{29}$ Ver Bertha Becker (1995: 293). Sobre as ideologias que movem as diversas organizações ecológicas, a geógrafa adverte: "Na medida em que todos os Estados têm hoje problemas, a competição se acirra e a ecologia é também utilizada pelos interesses dominantes atribuindo-lhe um papel na geopolítica mundial."(BECKER, 1995: 294).

${ }^{3 n} \mathrm{O}$ termo pré-capitalista não está sendo aplicado no sentido linear-evolucionista dos modos de produção; neste caso, a expressão indica sociedades não-capitalistas que, somente depois, por força do colonialismo europeu acabaram sendo "introduzidas" ao modo de produção hegemônico.

${ }^{31}$ Articulações que não se limitam às ramificações da Geografia, pois a geografia urbana, por exemplo, "comunica-se" com a sociologia urbana, com a antropologia, com o urbanismo, etc.; portanto são inúmeras as possibilidades de conexões da geopolítica ou da geografia política com várias áreas e sub-áreas do conhecimento acadêmico. 
se manifestam predominantemente em escala local permitem a análise, por exemplo, da organização política de um assentamento rural ${ }^{32}$ ou de uma nação indígena brasileira. O comércio ilegal de drogas e os efeitos sócio-espaciais em uma favela; ${ }^{33}$ a questão do controle e difusão das telecomunicações e os seus desdobramentos espaciais (AMORIM FILHO,1990: 18) ${ }^{34}$; o terrorismo (considerando-se as diferenças entre os grupos, como a Al Qaeda e o IRA.); a ação de ONGs na Amazônia; a expansão da OTAN no Leste Europeu; as iniciativas de ocupação do MST no Brasil ${ }^{35}$; os elevados níveis de organização polítića e territorial dos Chiapas; ${ }^{36}$ são temas que podem ser tratados sob ótica da geografia política/geopolítica, mas que exigem abordagens trans-escalares ${ }^{37}$. Segundo Carlos Walter Porto-Gonçalves (2005:13-14):

${ }^{32}$ Correlações entre a geografia política e a geografía agrária são perceptíveis no artigo de Cláudio Ubiratan Gonçalves (ver GONÇALVES, C. 2004) A importância das agências de mediação no ordenamento territorial dos assentamentos rurais. In: GEOgraphia: Revista de pós-graduação em Geografia da UFF. ; ano 6; $\mathrm{n}^{\circ} 11$.

${ }^{33} \mathrm{O}$ tráfico de drogas possibilita análises na escala metropolitana - e em rede urbana -; permite também realizar investigações nas escalas regionais quando incluídos os processos de produção agrícola, industrial, etc. Na escala metropolitana e das favelas ver, em especial, SOUZA, M. (1994) Dentre os vários trabalhos sobre o tema, Marcelo José Lopes de Sousa estabelece - automaticamente - importantes relações entre a geografia politica e a geografia urbana.

${ }^{34}$ Segundo Oswaldo Bueno Amorim Filho (1990:5-20), as recentes abordagens em Geografia Política deverão ser, necessariamente, trans-escalares e trans-temáticas (ver AMORIM FILHO, O. 1990. Por uma geografia política ampliada. In: Boletim de Geografia Teorética.; vol. 20; n³9).

${ }^{35}$ IRA (Exército Republicano Irlandês); OTAN (Organização do Tratado do Atlântico Norte); quanto às Organizações não governamentais (ONGs) é preciso também saber diferenciá-las. As geopolíticas do MST, além das estratégias de ocupação dos latifúndios improdutivos do Brasil, manifestam-se, também, nos processos de negociação com o Estado, na concepção de vida (e de produção) implementada nos assentamentos rurais, etc.

${ }^{36}$ Da geopolítica de Chiapas produziu-se, inclusive, um conhecimento sistematizado envolvendo sujeitos do próprio movimento, intelectuais, padres, escritores/funcionários do Estado, etc. Trabalhos diversos foram elaborados, como por exemplo: "Como a Europa vê os Zapatistas?"; "Sete características das guerrilhas latino-americanas"; "A autonomia indigena como ideal". Temas e assuntos de natureza política e geopolítica foram abordados no Fórum Especial para Reforma do Estado (realizado em junho-julho de 1996, em San Cristóbal de La Casas, no próprio estado de Chiapas) e no Primeiro Encontro Internacional pela Humanidade e Contra o Neoliberalismo; "Por primera vez en la historia de la humanidad un grupo armado rebelde es capaz de convocar a intelectuales, luchadores sociales, sindicalistas y ciudadanos de los cinco continentes a discutir un proyecto de construcción de un mundo distinto." (INSTITUTO DE INVESTIGACIONES ECONÓMICAS UNIVERSIDAD NACIONAL AUTÓNOMA DE MÉXICO, 1997: 99).

37 "(...) o lugar de cada escala específica não é o resultado mecânico de nenhuma das escalas (...)" (PORTO-GONÇALVES, 2005: 13). German Wettstein (1991: 46-70), apresenta vários temas pertinentes à geografia política no seu artigo "La Geografia Politica en el marco de una corriente de pensamiento geografico latinoamericano". 
De um ponto de vista emancipatório, o MST vem se constituindo como uma das principais expressões dessa nova configuração geográfico-politica do mundo, onde o campesinato se reinventa ${ }^{38}$ e tende, cada vez mais, a jogar um papel inovador nas novas configurações territoriais que estão sendo gestadas no mundo contemporâneo. (...) Outros sujeitos emergem à cena politica, e agora, mais do que nunca, os processos emancipatórios colocam-se para além das fronteiras nacionais; novas e complexas relações entre sujeitos e escalas geográficas colocam-se (...) pela ação interessada dos próprios sujeitos sociais (...)

Portanto, como já foi mencionado, outras organizações de poder e outras territorialidades (verificando as variações e conexões escalares) merecem ser exploradas no âmbito dos trabalhos em geopolítica/geografia política.

\section{Considerações finais}

Intensificam-se as aproximações da geografia politica com a geopolitica. De um lado, estudiosos que já, conscientemente, percebiam convergências originais e antigas, prosseguem hoje ampliando os laços positivos de ambas. Por outro lado, alguns pesquisadores resolveram aceitar essa aproximação talvez apenas por conveniência, tendo em vista as exigências decorrentes do contexto geopolítico mundial. Entretanto, para esses últimos, essa aproximação é apenas parcial, já que condenaram a geopolítica clássica à pena de morte. Além do mais, o pensarfazer geografia política/geopolítica - para esses estudiosos - deve-se restringir a uma elite cultural, amarrada corporativamente à academia. Em outra posição, persiste um pequeno grupo que ainda tenta "separar nitidamente" geopolítica de geografia política. Prevalece, neste caso, não uma "simples preocupação didática" em distinguir geografia política de geopolítica, mas a necessidade de execrar para sempre a geopolítica. Essa postura ideológica sustenta-se numa visão incompleta e compartimentada do passado e na pouca visibilidade dos processos geopolíticos em curso.

Importante registrar que muitos dos equívocos epistemológicos referentes à geografia política e a geopolitica decorrem de generalizações maniqueístas, de posicionamentos corporativos passionais, de pouca profundidade teórica e, de certa forma, resultam de insuficiência de conteúdo em relação aos trabalhos historicamente

\footnotetext{
${ }^{38}$ Nota do autor: "Talvez não haja formação social em que a expressão "reinvenção" seja tão redundante quanto no campesinato. Afinal, foi múltipla a sua convivência com outras formações envolventes ao longo da história." (PORTO - GONÇALVES, 2005:13).
} 
produzidos no interior dessas duas áreas de conhecimento. Esses posicionamentos, entretanto, permaneceram (um bom tempo) encobertos parcialmente por uma falsa dicotomia de ordem ideológica: a "pseudociência a serviço das classes dominantes" versus a "disciplina teórica, séria e às vezes dotada de senso crítico". Esse "mito" empobrecedor e reducionista está dissolvendo-se nos centros acadêmicos que, hegemonicamente, assumiram essa posição ideológica? Uma investigação/ interpretação epistemológica mais cuidadosa revela que tanto a geografia política quanto a geopolítica produziram conhecimentos comprometidos com a dominação de grupos, povos, nações, etc. (talvez a geopolitica um pouco mais do que a geografia política ?); mas também ambas - variavelmente - construíram trabalhos críticos e reflexivos em relação aos Estados e suas políticas internas e externas.

Sobre os objetos de pesquisa em geografia política/geopolítica, há uma tendência à ampliação; o "anacronismo persistente" em relação aos Estados nacionais está, paulatinamente, sendo ultrapassado pelos novos estudos que consideram também outras instâncias de poder e outras territorialidades. Porém, alguns desses estudos não assumiram explicitamente, ainda, a sua correlação temática com a geopolítica/ geografia política. Evidentemente que as abordagens referentes aos Estados nacionais continuam importantes, inclusive, em razão do novo papel político que os mesmos estão (diferentemente) construindo no atual contexto. Neste âmbito, a transescalaridade - exercício tão tradicional e tranqüilo aos geógrafos - adquire posição metodológica de maior envergadura nos trabalhos em geopolítica/geografia política.

Por fim, vale destacar que expressões como "geopolítica crítica", "geopoliitca libertária", "geografia política renovada", "geografia política ampliada" (dentre outras), manifestam leituras que ultrapassam velhas divergências, indicam também consideração às antigas convergências e apontam na direção de novas possibilidades e métodos de pesquisa envolvendo a geopolítica e a geografia política.

\section{GEOGRAFIA POLÍTICAE GEOPOLÍTICA: VELHAS E NOVAS CONVERGÊNCIAS}

Resumo: Alguns pesquisadores - geógrafos, historiadores, cientistas políticos, etc aproximam, conceitualmente, geopolítica de geografia política. Entretanto, outros pesquisadores fazem questão de diferenciar ambas nomenclaturas. Outro problema referese à ampliação dos objetos de pesquisa dessas áreas de conhecimento. É apresentada, na primeira parte deste artigo, uma reflexão sobre os significados atribuídos às nomenclaturas - geografia política e geopolítica - contrapondo-se, então, as duas vertentes citadas. A segunda parte trata da questão dos objetos de pesquisa. Espera-se contribuir para a desmistificação e a ruptura de alguns conceitos e preconceitos concernentes à geografia política e à geopolítica.

Palavras-chave: Geografia Política; Geopolítica; Nomenclaturas; Ideologia.

\section{POLITICAL GEOGRAPHY AND GEOPOLITICS: NEW ANDOLD CONVERGENCES}

Abstract: Some researchers (geographers, historians, political scientists, and others) think that the terms Geopolitics and Political Geography have similar concepts, while others 
prefer to make clear that they are different. Another problem is the increasing number of subjects both sciences have been dealing with. The first part of this paper shows a study of the meaning of these two terminologies, according to these two opposite groups of researchers. The second part is about the subjects of these sciences. The main point of this work is to clarify the meaning of these two terminologies.

Keywords: Political Geography; Geopolitics; Terminologies; Ideology

\section{BIBLIOGRAFIA}

AMORIM FILHO, O. (1990). Por uma Geografia Política ampliada In Boletim de Geografia Teorética. Vol.20; n 39. Rio Claro: Associação de Geografia Teorética.

ANDRADE, M. (1989). Geopolítica do Brasil. SP: Ática.

BECKER, B. (1995) A geopolítica na virada do milênio: logística e desenvolvimento sustentável. In: Geografia: conceitos e temas. RJ: Bertrand Brasil.

CLAVAL, P. (1979). Espaço e poder. RJ: Zahar.

COSTA, W. (1992). Geografia Política e Geopolítica. São Paulo: Hucitec/USP. (1992). O Estado e as Politicas Territoriais do Brasil. São Paulo: Contexto.

EVANGELISTA, H. (1995). Introdução à geopolítica. In: SANTOS, M. et.al. (orgs.) O novo mapa do mundo - Problemas geográficos de um novo mundo. SP: Hucitec - ANPUR.

GONÇALVES, C. (2004) A importância das agências de mediação no ordenamento territorial dos assentamentos rurais. In: GEOgraphia: Revista de pós graduação em Geografia da UFF. ; ano 6; n $^{\circ} 11$; Niterói/RJ: UFF/EGG. INSTITUTO DE INVESTIGACIONES ECONÓMICAS - UNIVERSIDAD NACIONAL AUTÓNOMA DE MÉXICO. (1997) Chiapas. México, .D. F.: Era.

LACOSTE, Yves. (1997). A Geografia - isso serve, em primeiro lugar, para fazer a guerra. $4^{\circ}$ ed. SP: Papirus.

MIYAMOTO, S. (1985). Geopolítica e poder no Brasil. SP: Papirus.

MORAES, A. C. R. (org.) (1990). Ratzel - geografia. SP: Ática.

POULANTZAS, N. (1980). O Estado, o poder, o socialismo. RJ: Graal.

PORTO-GONÇALVES, C. W. (2002). O latifúndio-genético e a r-exiștência indígeno camponesa. In: GEOgraphia: Revista de pós-graduação em Geografia da UFF, ano 4; ${ }^{\circ}$ 8; Niterói/RJ: UFF/EGG.

(2005) A nova questão agrária e a reinvenção do campesinato: o caso do MST. In: Geografias:Revista do Departamento de Geografia e do Programa de Pós-graduação em Geografia do IGC-UFMG. Vol. 1, $\mathrm{n}^{\circ} 1$; Belo Horizonte: UFMG.

RAFfestiN, C. (1993). Por uma Geografia do Poder. São Paulo: Ática. 
SOUZA, M. (1994). O tráfico de drogas no Rio de Janeiro e seus efeitos negativos sobre o desenvolvimento sócio-espacial. In:Cadernos IPPUR.; ano VIII, $\mathrm{n}^{\circ} 2 / 3$, set./dez; RJ: UFRJ.

TRAGTENBERG, M. (org.) (1987). Kropotkin. Textos escolhidos. RGS e SP: L \& PM.

VESENTINI, J.(1987). A capital da geopolítica. $2^{\circ}$ ed.. SP: Ática.

. (1997). O apogeu e o declínio da geopolítica. In: Revista do Departamento de Geografia - n 11, SP: FFLCH - USP.

(2000). Novas geopolíticas. SP: Contexto.

WETTSTEIN, G. (1991). La Geografia Politica en el marco de una corriente de pensamiento geografico latinoamenricano. In: GEOSUL - Revista do Departamento de Geociências - CFCH/UFSC - ${ }^{\circ} 10$; ano V; $2^{\circ}$ semestre de 1991; Florianópolis: UFSC. 